\title{
Inactivation of EMILIN-1 by Proteolysis and Secretion in Small Extracellular Vesicles Favors Melanoma Progression and Metastasis
}

\author{
Ana Amor López ${ }^{1}$, Marina S. Mazariegos ${ }^{1}$, Alessandra Capuano ${ }^{2}$ (D) Pilar Ximénez-Embún ${ }^{3}$, \\ Marta Hergueta-Redondo ${ }^{1}$, Juan Ángel Recio ${ }^{4} \mathbb{D}$, Eva Muñoz ${ }^{5}$, Fátima Al-Shahrour ${ }^{6} \mathbb{D}$, Javier Muñoz ${ }^{3}$, \\ Diego Megías ${ }^{7}$, Roberto Doliana ${ }^{2}$, Paola Spessotto ${ }^{2}$ iD and Héctor Peinado ${ }^{1, * \mathbb{D}}$
}

check for updates

Citation: Amor López, A.;

Mazariegos, M.S.; Capuano, A.; Ximénez-Embún, P.; HerguetaRedondo, M.; Recio, J.Á.; Muñoz, E.; Al-Shahrour, F.; Muñoz, J.; Megías, D.; et al. Inactivation of EMILIN-1 by Proteolysis and Secretion in Small Extracellular Vesicles Favors Melanoma Progression and Metastasis. Int. J. Mol. Sci. 2021, 22, 7406. https://doi.org/10.3390/ ijms22147406

Academic Editor: Frank Gieseler

Received: 2 June 2021

Accepted: 23 June 2021

Published: 9 July 2021

Publisher's Note: MDPI stays neutral with regard to jurisdictional claims in published maps and institutional affiliations.

Copyright: (c) 2021 by the authors. Licensee MDPI, Basel, Switzerland. This article is an open access article distributed under the terms and conditions of the Creative Commons Attribution (CC BY) license (https:// creativecommons.org/licenses/by/ $4.0 /)$.
1 Microenvironment and Metastasis Laboratory, Molecular Oncology Programme, Spanish National Cancer Research Center (CNIO), 28029 Madrid, Spain; anaamorlopez@gmail.com (A.A.L.); scopg@hotmail.com (M.S.M.); mhergueta@cnio.es (M.H.-R.)

2 Unit of Molecular Oncology, Centro di Riferimento Oncologico di Aviano (CRO), Department of Advanced Cancer Research and Diagnostics, IRCCS, I-33081 Aviano, Italy; acapuano@cro.it (A.C.); rdoliana@cro.it (R.D.); pspessotto@cro.it (P.S.)

3 Proteomics Unit-ProteoRed-ISCIII, Spanish National Cancer Research Centre (CNIO), 28029 Madrid, Spain; mpximenez@cnio.es (P.X.-E.); jmunozpe@cnio.es (J.M.)

4 Biomedical Research in Melanoma-Animal Models and Cancer Laboratory, Vall d'Hebron Research Institute VHIR-Vall d'Hebron Hospital Barcelona-UAB, 08035 Barcelona, Spain; juan.recio@vhir.org

5 Clinical Oncology Program, Vall d'Hebron Institute of Oncology-VHIO, Vall d'Hebron Hospital, Barcelona-UAB, 08035 Barcelona, Spain; emunoz@vhio.net

6 Bioinformatics Unit, Structural Biology Programme, Spanish National Cancer Research Centre (CNIO), 28029 Madrid, Spain; falshahrour@cnio.es

7 Confocal Microscopy Unit, Biotechnology Programme, Spanish National Cancer Research Center (CNIO), 28029 Madrid, Spain; dmegias@cnio.es

* Correspondence: hpeinado@cnio.es

\begin{abstract}
Several studies have demonstrated that melanoma-derived extracellular vesicles (EVs) are involved in lymph node metastasis; however, the molecular mechanisms involved are not completely defined. Here, we found that EMILIN-1 is proteolyzed and secreted in small EVs (sEVs) as a novel mechanism to reduce its intracellular levels favoring metastasis in mouse melanoma lymph node metastatic cells. Interestingly, we observed that EMILIN-1 has intrinsic tumor and metastasis suppressive-like properties reducing effective migration, cell viability, primary tumor growth, and metastasis. Overall, our analysis suggests that the inactivation of EMILIN-1 by proteolysis and secretion in sEVs reduce its intrinsic tumor suppressive activities in melanoma favoring tumor progression and metastasis.
\end{abstract}

Keywords: EMILIN-1; small extracellular vesicles; metastasis; melanoma

\section{Introduction}

The tumor microenvironment has been found to play an active role in tumor progression [1]. Tumors induce the formation of microenvironments at distant organs that are conducive to the survival and outgrowth of tumor cells prior to their arrival at these sites. These microenvironments were termed "pre-metastatic niches" (PMNs) [2]. This concept proposes the ability of primary tumor cells to precondition regional and distal organs for future metastatic disease before the arrival of circulating tumor cells via tumor-derived factors. Therefore, PMNs represent an abnormal and favorable microenvironment for metastasis [2].

Several reports have highlighted the role of extracellular vesicles (EVs) during PMN formation [3,4]. EVs are composed of a lipid bilayer that contains molecular cargo representative from the cell of origin (e.g., proteins, RNA, DNA, etc.) [5]. EVs mediate cell-cell 
communication by several mechanisms, from inducing intracellular signaling after their interaction, to confer new properties due to the acquisition of new receptors, enzymes, or even genetic material after their uptake [6]. EVs can be classified based on their origin and size. A recent classification based on size divided them into large (lEVs) and small EVs (sEVs) [7], whereby microvesicles, apoptotic bodies and oncosomes can be considered lEVs, yet smaller vesicles like exosomes and exomeres are considered sEVs [7]. SEVs serve as a vehicle for horizontal transfer of molecules such as RNAs, DNA, and proteins which, once in the target cell, can exert their function [4-6,8,9]. The International Society for Extracellular Vesicles (ISEV) released MISEV guidelines in 2018 [10] detailing the minimum criteria for confirming isolation of EVs. In this work, we ensured to follow MISEV guidelines recommend [10], such as (i) defining quantitatively the source of EVs, (ii) characterization of the abundance of $\mathrm{EV}$ particle number and protein content, (iii) proteomic characterization, and (iv) purity of the preparation.

Tumors induce changes in the sentinel LN (LNs) such as enhanced lymphangiogenesis [11,12], induction of an immunosuppressive environment, and increased vascular flow $[13,14]$. These changes precede metastatic colonization and contribute to the formation of the PMN in the LNs $[11,13,14]$. Understanding the mechanisms involved in LN metastasis is crucial to define the first steps of melanoma metastatic spread. Given that $\mathrm{sEVs-derived} \mathrm{from} \mathrm{melanoma} \mathrm{cells} \mathrm{promote} \mathrm{lymphangiogenesis,} \mathrm{extracellular} \mathrm{matrix}$ (ECM) remodeling, immunosuppression, and metastasis in LNs $[15,16]$, in this work we wanted to analyze if sEVs derived from lymph node metastatic melanoma cells have a specific signature that may favor tumor lymph nodes. For this purpose, we used the B16-F1R2 model, a lymph node metastatic melanoma cell line generated by the group of Dr. Michael Detmar [17]. In comparison to other B16 variants, B16-F1R2 was injected intracutaneously and B16-F1R2 was isolated from metastatic lymph nodes and it is a useful model to understand lymph node metastasis in mouse melanoma models [17]. We have found a specific signature of genes over-expressed in cells and proteins hyper-secreted in sEVs including EMILIN-1, a protein involved in lymph node physiology and pathology $[18,19]$. Elastin microfibrillar interface proteins (EMILINs) constitute a four-member family of glycoproteins with a C-terminus gC1q domain typical of the gC1q/TNF superfamily members and also contain N-terminus unique cysteine-rich EMI domain [20]. EMILIN-1 has been characterized in multiple scenarios such as cell migration [21] and proliferation [20], cell migration [21], lymphatic vessel function [22] skin homeostasis [23], and cancer development [19].

In this work, we found that EMILIN-1 is proteolyzed and secreted in sEVs as a mechanism to reduce its intracellular levels in B16-F1R2 cell line. In order to analyze the relevance of our findings, we overexpressed EMILIN-1 in B16-F1 cells and found a reduction of effective migration and cell viability, suggesting that EMILIN-1 has intrinsic tumor suppressive activities in melanoma. Noteworthy, EMILIN-1 overexpression led to reduced primary tumor and lymph node metastasis in B16-F1 mouse melanoma xenograft models. Overall, our data suggest that the proteolysis of EMILIN-1 and its secretion in sEVs is a novel mechanism of EMILIN-1 inactivation favoring melanoma metastasis.

\section{Results}

\subsection{Characterization of Secreted sEVs in Melanoma Models}

We have characterized secreted sEVs from a panel of mouse melanoma models representative of low metastatic potential (B16-F1), high metastatic potential (B16-F10), and lymph node metastasis (B16-F1R2) [17] (Figure 1A). We first isolated by ultracentrifugation and characterized secreted sEVs from the melanoma models described. Analysis of protein in secreted sEVs demonstrated that, congruently with our previous published data [24], the lymph node metastatic cell line (B16-F1R2) and the high metastatic model (B16-F10) secrete increased protein cargo in sEVs than the poorly metastatic cell line B16-F1 (Figure 1B,C). Analysis by nanoparticle tracking analysis showed a typical distribution size of sEVs with similar mean and mode (Supplementary Figure S1A-C). Particle number showed a ten- 
dency to increase in B16-F10 cells but was not significant. (Supplementary Figure S1D).
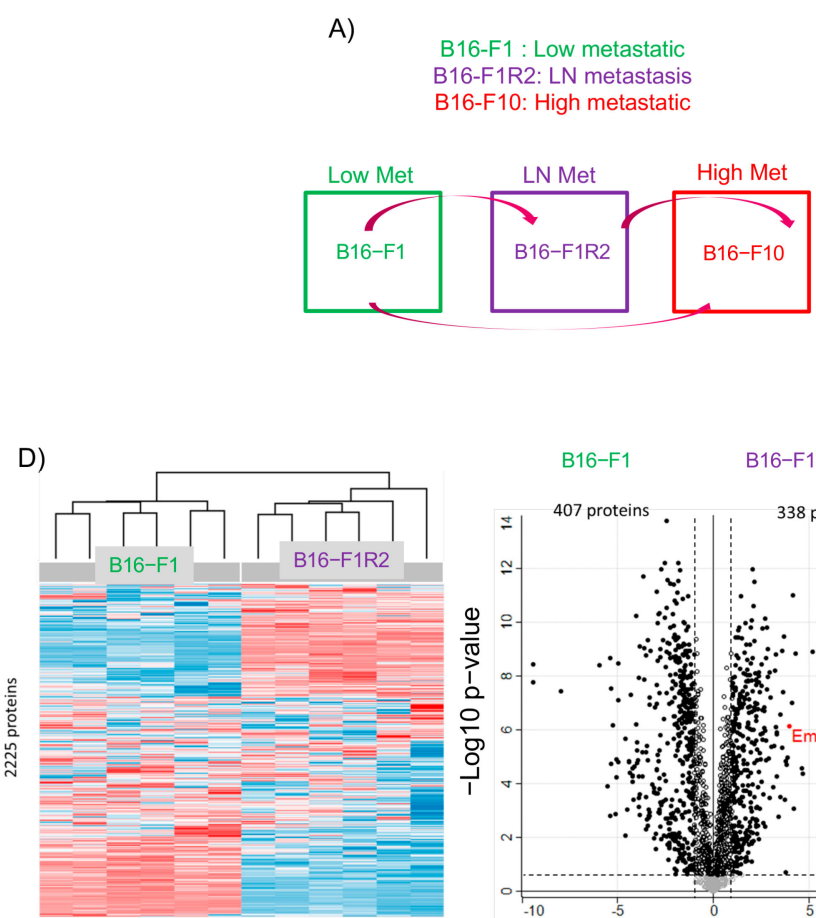

Low $1-2.5 \overbrace{}^{\text {Z-score }} 0$ +2.5 High

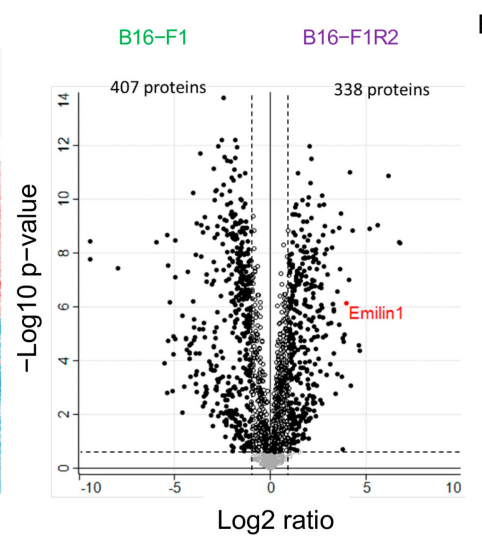

B)

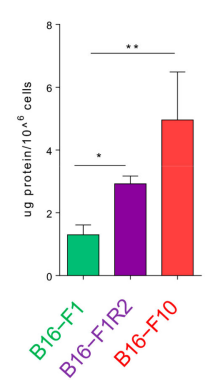

E)

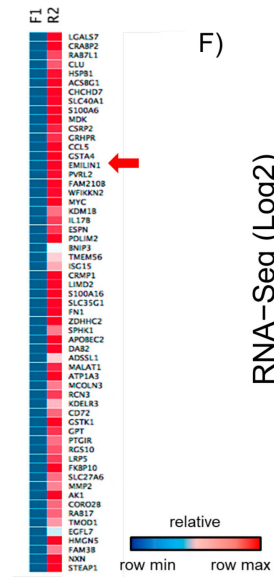

C)
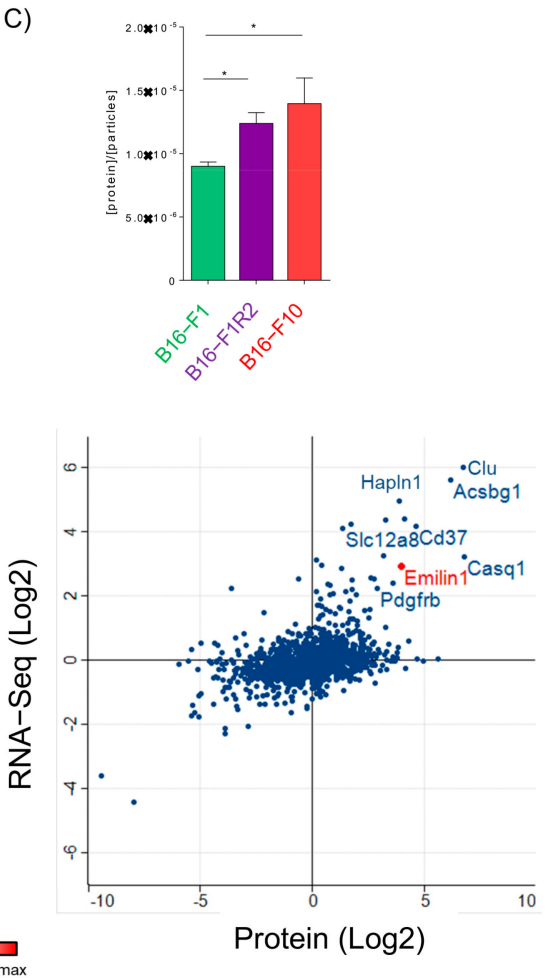

Figure 1. Defining the proteomic signature of sEVs secreted from lymph node metastatic melanoma models. (A) Schematic representation of the mouse melanoma models used. (B) Analysis of sEV number secretion and (C) total protein secreted in sEVs in mouse melanoma cells lines derived from low metastatic model (green), lymph node metastasis (purple) and distal metastasis (dark purple and red). $n=5 .{ }^{*} p<0.05,{ }^{* *} p<0.01$ using Mann Whitney test. (D) Unsupervised hierarchical clustering. 2225 proteins were identified in sEVs derived from B16-F1 and B16-F1R2 cell lines. To the right, a volcano plot showing the differentially expressed proteins (Student's $t$-test, $p<0.05$ ). Black circles represent proteins above the fold change cutoff. (E) Heatmap of genes differentially expressed in B16-F1R2 compared to B16-F1. As noted by the arrow, EMILIN-1 is over-expressed in both cell lines. (F) Correlation of proteomic and transcriptomic data to define the main genes overexpressed and proteins hyper-secreted in sEVs from B16-F1R2 compared to B16-F1 cell line.

To investigate the proteomic signatures in the sEVs associated with the lymph node metastatic melanoma model B16-F1R2, we collected sEVs from this model and the parental B16-F1 model and performed mass spectrometry analysis (Figure 1D). We identified 2225 proteins in the sEVs derived from these models and confirmed that samples clustered by cell line after performing unsupervised hierarchical clustering analysis (Figure 1D). Differential analysis showed that $33 \%$ of the proteins were significantly regulated. Among them, we found 338 upregulated proteins in B16-F1R2-derived sEVs compared to parentalderived sEVs suggesting the existence of a proteomic signature associated with the LN metastatic model. Specifically, we found an enrichment in proteins that related ECM to organization (Supplementary Figure S2).

We performed RNA sequencing in B16-F1, B16-F1R2 cells (Supplementary Table S1, example of cluster Figure 1E) and correlated the protein cargo secreted in sEVs with gene expression data in B16-F1 and B16-F1R2 cells (Supplementary Table S2). We observed that some overexpressed genes belonged to proteins hyper-secreted in sEVs from B16-F1R2. Interestingly, out of several candidates we selected EMILIN-1, a protein related to ECM and lymph node remodeling [23], that was hyper-secreted in sEVs and also overexpressed at the mRNA level (Figure 1F, Supplementary Table S2). 


\subsection{EMILIN-1 Is Proteolyzed and Secreted in sEVs from B16-F1R2 Cell Line}

Analysis of EMILIN-1 expression by qPCR showed that while it is highly expressed in melanocytes (melan-a), its levels were downregulated level in B16-F1 and then re-expressed in B16-F1R2 and F10 at mRNA (Figure 2A). Importantly, analysis of EMILIN-1 expression by Western-blot using specific antibodies [19] in mouse melanoma models demonstrated that it is not detected intracellularly in any of the tested cell lines but interestingly it is secreted in sEVs derived from LN metastatic model B16-F1R2 (Figure 2B, left panels, cells), which let us hypothesize that EMILIN-1 could be detected extracellularly in sEVs. Indeed, supporting our mass spectrometry data, EMILIN-1 was detected in sEVs but with several bands with a lower molecular weight than expected $(150 \mathrm{KDa})$ as opposed to the full-length protein used as a positive control (Figure 2B, right panels, sEVs), supporting its proteolysis. Interestingly EMILIN-1 has been previously reported to be inactivated by proteolysis in other models [25,26], suggesting that secretion and proteolysis of this protein in melanoma cells could be a novel mechanism of its inactivation.

A)

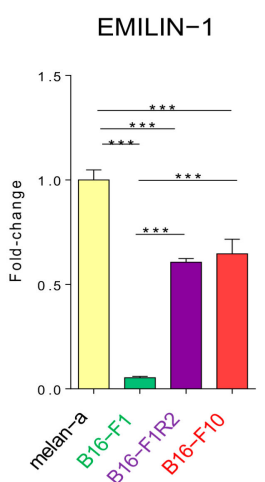

B)

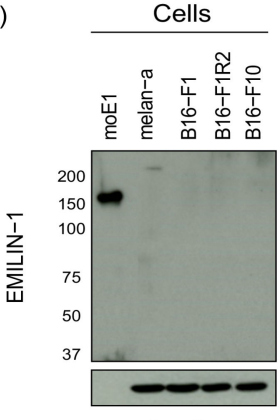

$\beta$-actin

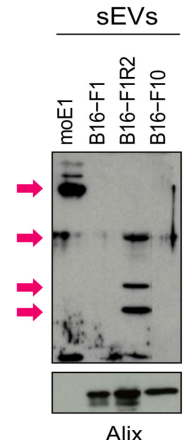

Alix
C)

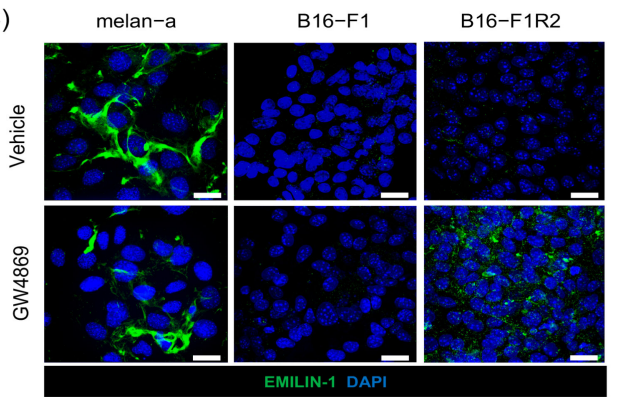

D)

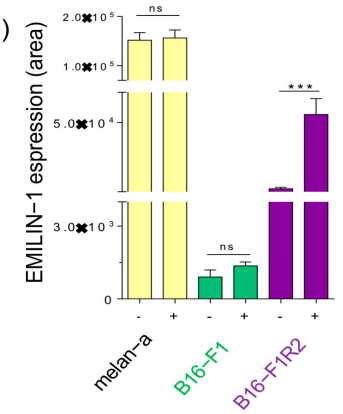

Figure 2. EMILIN-1 is degraded and secreted in sEVs from B16-F1R2 cell line. (A) mRNA expression levels by qRT-PCR of EMILIN-1 $(n=2)$, ${ }^{* * *} p<0.001$ using Mann Whitney test. (B) Analysis by Western-blot of EMILIN-1 in mouse cell line models and derived sEVs (B16-F1, B16-F1R2, and B16F10). moE1, EMILIN-1 recombinant mouse protein, was used as loading positive control, molecular weight expected is $150 \mathrm{kDa}$ indicated by an arrow. Anti-EMILIN-1 antibody detected several bands with a lower molecular weight than expected in secreted sEVs, indicated by an arrow. (C) Analysis of EMILIN-1 (in green) expression and localization by confocal immunofluorescence (scale $18 \mu \mathrm{m}$ ) in melanocytes, B16-F1 and B16-F1R2 cell lines before and after the treatment with $10 \mu \mathrm{M}$ GW4869 during $24 \mathrm{~h}$. Cell nuclei were stained with DAPI (in blue). (D) Quantification of EMILIN-1 expression (green signal) in $(\mathbf{C}),{ }^{* * *} p<0.001$, ns: non-significant, by Non-parametric $t$-test.

We next decided to analyze if EMILIN-1 secretion in sEVs could be inhibited by the use of the EV secretion inhibitor GW4869, a non-competitive inhibitor of sphingomyelinase. In agreement with WB and RNA expression data, we observed that EMILIN-1 is expressed and deposited in the ECM by melan-a cell line, however, is not detected in B16-F1 and B16-F1R2 cells (Figure 2C, upper panels). Treatment with GW4869 did not affect EMILIN-1 in melan-a and B16-F1 cells (Figure 2C, lower left, and middle panels), suggesting that extracellular deposition of EMILIN-1 by melan-a cells is not mediated by EV secretion. However, we observed a significant accumulation of EMILIN-1 in the B16F1-R2 cell line after treatment 
with GW4869 (Figure 2C, lower right panel). We performed similar studies but using the proteasome inhibitor MG-132, a potent, reversible, and cell-permeable proteasome inhibitor and reduces the degradation of ubiquitin-conjugated proteins in mammalian cells $[27,28]$. We observed that EMILIN-1 levels remained similar after MG-132 treatment in all cell types, suggesting that proteasome inhibition does not affect EMILIN-1 levels. (Supplementary Figure S3). These data showed that inhibition of EV secretion avoids EMILIN-1 secretion extracellularly in the B16-F1R2 cell line.

\subsection{EMILIN-1 Overexpression Reduces Cell Viability and Effective Migration}

Since EMILIN-1 has been already reported to have tumor suppressive like functions $[19,29]$, we postulated that melanoma cells secrete and degrade EMILIN-1 in sEVs as a novel mechanism to inactivate its suppressive signals in melanoma. To define the intrinsic role of EMILIN-1 in melanoma cells, we performed cell viability and cell cycle assays. We first analyzed cell viability in B16-F1-HA control cells or cells overexpressing HA-EMILIN-1 (B16-F1-HA-E1). To define the effects on cell proliferation we analyzed a number of viable cells at different time points $(24,48$, and $72 \mathrm{~h}$ ). We observed that overexpression of EMILIN-1 reduced significantly B16-F1 cell viability in three different clones analyzed (Figure 3A). To determine if this reduction was due to changes in cell cycle, we analyzed cell cycle histograms for bulk DNA staining (PI), after the addition of EdU, in B16-F1-HA and B16-F1- HA-E1 cells after 24h, 48h, 72h, $96 \mathrm{~h}$ (Figure 3B). We found that EMILIN-1 overexpression does not significantly affect the cell cycle in B16-F1 cells. These results suggest that EMILIN-1 affect mainly the metabolic balance and cell viability in cells but not the cell cycle of the cells. Analysis of the percentage of cells in the S phase was then calculated. We found that EMILIN-1 overexpression does not affect significantly cell cycle compared to B16-F1-HA control cells (Figure 3C). Then, we performed melanoma cell migration tracking assays in B16-F1-HA and B16-F1-HA-E1 cells. We observed in their trajectory reconstruction that there is a loss of migration directionality in cells overexpressing EMILIN-1 compared to control cells B16-F1-HA cells that had a defined migration (Figure 3D). These data suggest that increased EMILIN-1 levels reduce effective migration in melanoma cells. Therefore, it is plausible that reduction of intracellular EMILIN-1 levels observed along melanoma progression could be required for efficient and independent migration, a well-known property of melanoma cells. 
A)

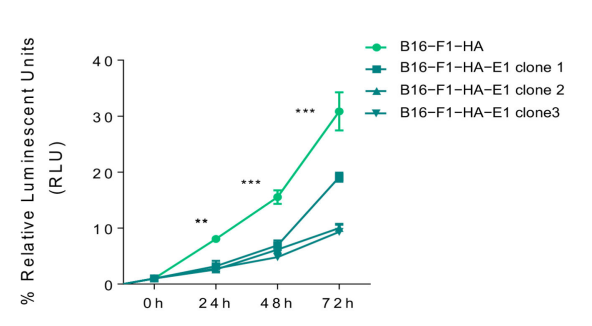

D)

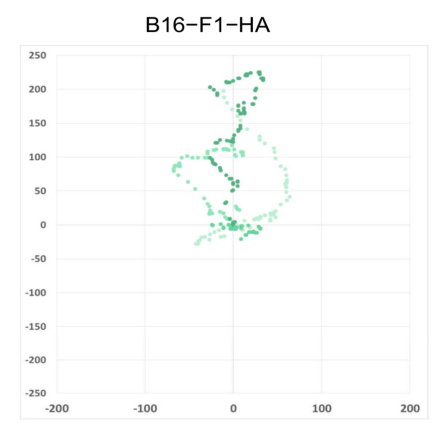

B)
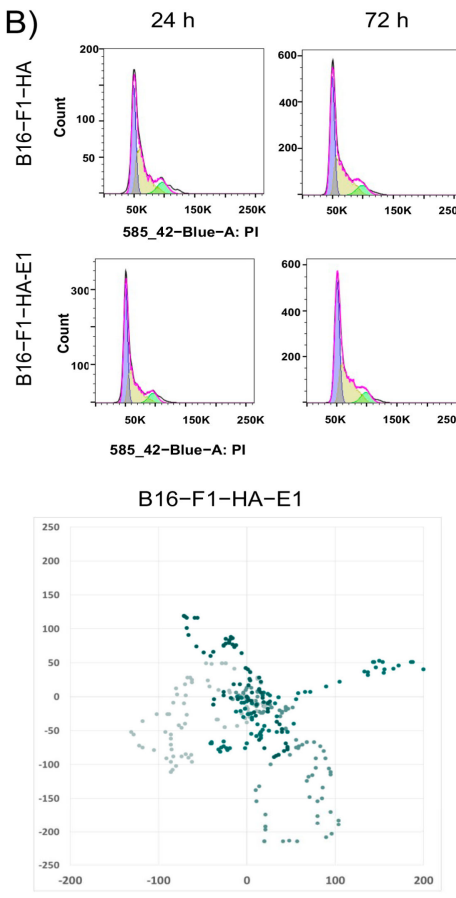

$72 \mathrm{~h}$
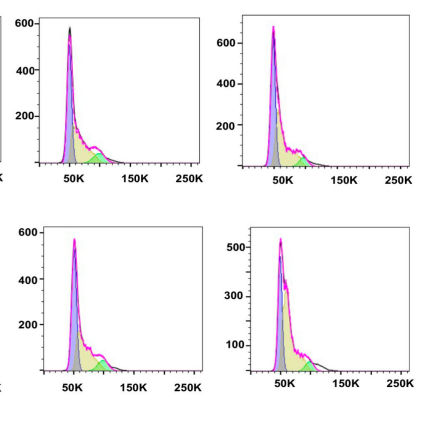

C)

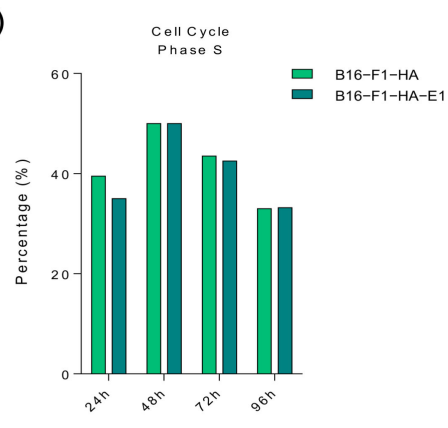

E)

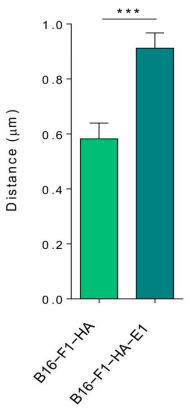

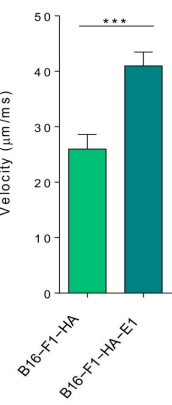

Figure 3. EMILIN-1 overexpression reduces cell viability and directionality cell migration. (A) Analysis of cell viability using CellTiter-Glo ${ }^{\circledR}$ Luminescent Cell Viability Assay after EMILIN-1 expression of B16-F1-HA and different clones of B16-F1-HA cells overexpressing EMILIN-1 at indicated time point $(n=2) * * p<0.01$ and ${ }^{* * *} p<0.001$ by 2 - way ANOVA. Relative Luminescent Units (RLU) are represented in y axis. (B) Representative histograms showing the cell cycle distribution in B16-F1-HA and B16-F1- HA-E1 models at 24, 72 and $96 \mathrm{~h}$. (C) Relative changes in the percentage of B16-F1-HA and B16-F1-HA-E1 cells in S phase after addition of Edu. (D) Representative examples of cell tracking and motility analysis in B16-F1-HA and B16-F1-HA-E1 models. (E) Distance and velocity of cell tracking analysis by Image software ${ }^{* * *} p<0.001$ by Unpaired $t$-test.

\subsection{EMILIN-1 Overexpression Reduces Primary Tumor Growth and Lymph Node Metastasis}

We next analyzed the effect of EMILIN-1 overexpression in tumor growth and metastatic properties of B16-F1 cells. For this purpose, C57BL/ 6 mice were injected subcutaneously with B16-F1-HA control cells or cells overexpressing EMILIN-1 (B16-F1- HA-E1). We found that EMILIN-1 overexpression led to a significant reduction of tumor growth (Figure 4A). Moreover, analysis of lymph node metastasis after intra-footpad injection showed a reduction of lymph node metastasis after EMILIN-1 overexpression (Figure 4B,C). These data support that EMILIN-1 overexpression reduces both primary tumor growth and lymph node metastasis in B16-F1 cells. 
A)

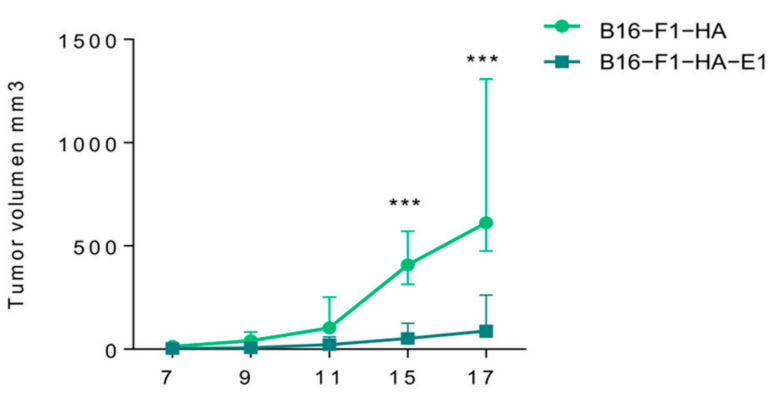

B)

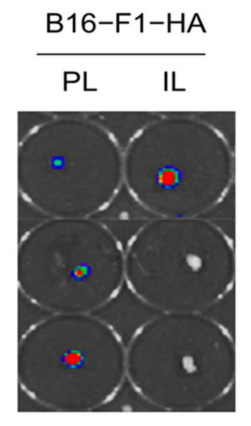

C)

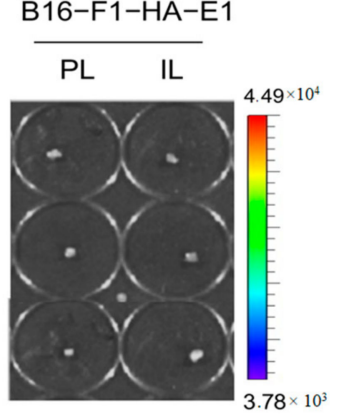

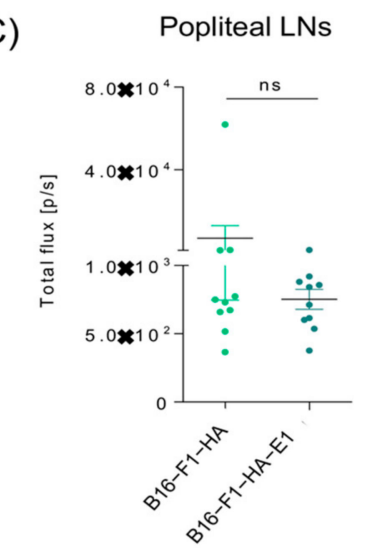

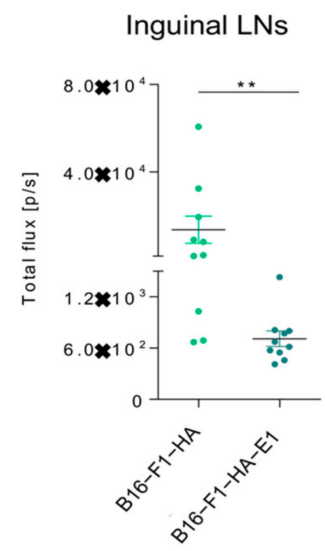

Figure 4. Overexpression of EMILIN-1 reduce tumor growth and lymph node metastasis. (A) Growth of subcutaneous xenografts established from B16-F1 and B16-F1-HA E1 cells $\left(n=5\right.$ per group) ${ }^{* * *} p<0.001$ by 2 -way ANOVA. (B) in vivo imaging of popliteal and inguinal lateral LNs, from intrafootpad injected mice from B16-F1-HA andB16-F1-HA-E1 cells. (C) Total flux ( $\mathrm{p} / \mathrm{s}$, photons per second) quantification of popliteal and inguinal $\mathrm{LN}, n=10 * *<<05$ by Nonparametric t-test.

\subsection{EMILIN-1 Stabilization Leads to Reduced Lymph Node Metastasis}

Among all the proteolytic enzymes released by the tumor, neutrophil elastase (NE) was found as the main enzyme able to fully impair the regulatory function of EMILIN-1 in sarcoma and ovarian cancer $[19,29]$. The consequence of this proteolytic process was the impairment of its anti-proliferative role [22,29]. The local administration of Sivelestat, an inhibitor of neutrophil elastase prevents EMILIN-1 degradation and reduces lymphoedema, restoring a normal lymphatic functionality in a mouse lymphoedema model [22,29]. Analysis by site direct mutagenesis in 914 residues of EMILIN-1 demonstrated that mutant R914W was resistant to NE proteolytic cleavage [22,29]. Based on this, we next analyzed the effect of the stabilization mutant of EMILIN-1 (E1-R914W) [22,29] in B16-F1R2 cells in primary tumor growth and metastasis. We observed that while EMILIN-1 stabilization mutant did not affect significantly primary tumor growth (Figure 5A,B), it reduced significantly spontaneous lymph node metastasis (Figure 5C,D). We also analyzed the effect in lymph node experimental metastasis after footpad injection and we observed that EMILIN-1 stabilization mutant expression reduced lymph node metastases (Figure 5E-G). 
A)

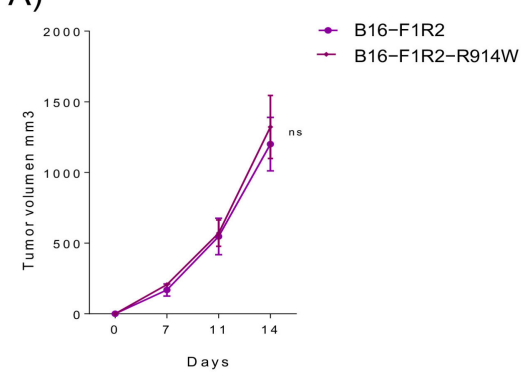

E)

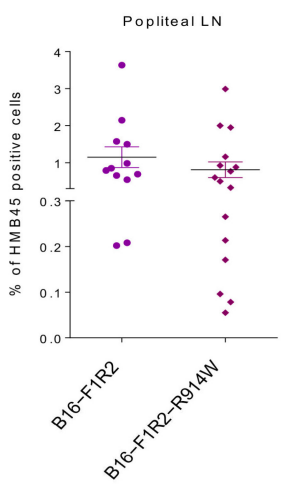

B)

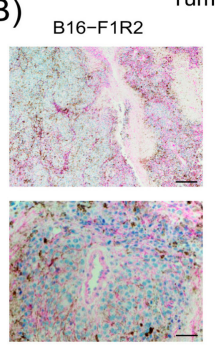

F)

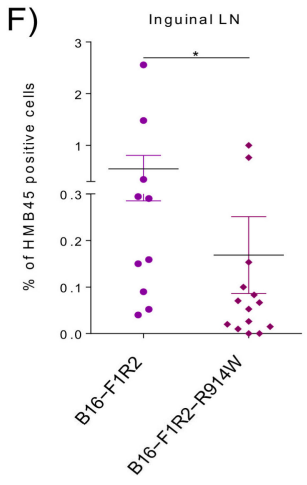

C)

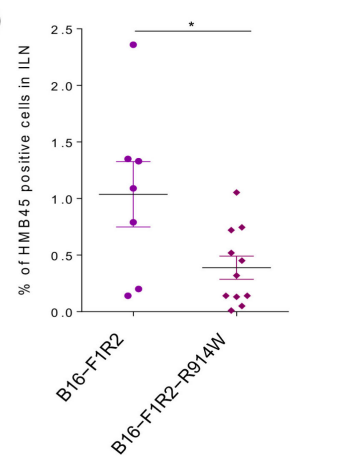

B16-F1R2-R914W
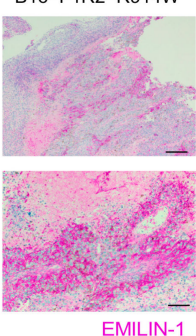

G)

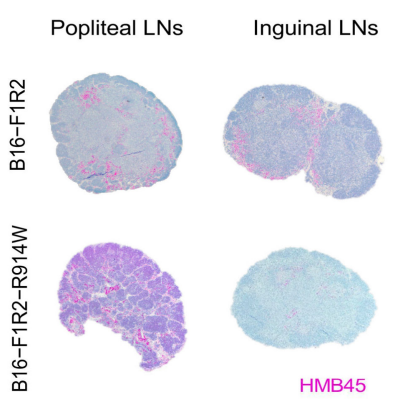

D) Inguinal LNs

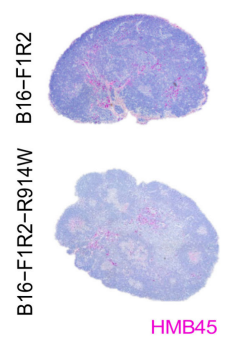

Figure 5. Analysis of EMILIN-1 stabilization mutant in vivo. (A) Tumor growth and lymph node metastasis of B16-F1R2 and B16-F1R2-R914W xenografts. C57BL/ 6 mice were injected subcutaneously with $1 \times 10^{6}$ B16-F1R2 $(n=8$ mice $)$ and B16-F1R2-R914W ( $n=10$ mice) cells. (B) Representative images of B16-F1R2 and B16-F1R2-R914W tumor sections stained for EMILIN-1. Bar: $100 \mu \mathrm{m}$ (C) Percentage of melanoma HMB45 positive cells quantification from inguinal lymph nodes were used for analyzed lymph node metastasis (B16-F1R2, $n=7$ and B16-F1R2-R914W, $n=13$ ) ${ }^{*} p<0.05$ by Non-parametric $t$-test. (D) Representative images of inguinal lymph nodes (HMB45 staining) from B16-F1R2 and B16-F1R2 R914W xenografts. Bar: $500 \mu \mathrm{m}$. (E-G) Analysis of lymph nodes from C57BL/6 mice injected intrafootpad with 200,000 B16-F1R2 and B16-F1R2R914W cells. Percentage of melanoma HMB45 positive cells quantification from (E) popliteal (B16-F1R2 group $n=12$ and B16-F1R2-R914W group $n=16$ ) and (F) inguinal lymph nodes (B16-F1R2 group $n=10$ and B16-F1R2-R914W group $n=14$ ), ${ }^{*} p<0,05$ by Non-parametric $t$-test. (G) Representative images of popliteal and inguinal lymph nodes (HMB45 staining) from C57BL/6 mice. Bar: $500 \mu \mathrm{m}$.

\section{Discussion}

During the last years, several studies have demonstrated that EVs play an important role in cell-cell communication being actively involved in tumor progression and metastasis [30]. Data support that tumor-derived EVs are key players in the formation of pre-metastatic niche formation at distal sites and metastatic organotropism [2]. Consistent with this, tumor-derived $\mathrm{sEV}$ can reach the sentinel lymph nodes favoring metastatic spread $[15,16]$. Indeed, they have been proposed to play a role in lymph node pre-metastatic niche formation [11]. It has been previously reported that metastatic melanoma models secrete higher amounts of proteins in sEV as compared to low metastatic models [24]. In addition, sEV protein concentrations are higher in the plasma and seroma of melanoma subjects with higher stages (III, IV) compared to lower stages (I, II) and subjects without cancer $[24,31]$. In agreement with that, we observed that sEVs from lymph node metastatic (B16-F1R2) and high metastatic models (B16-F10) secrete higher amounts of protein in sEV than poorly metastatic cell line B16-F1. However, the gene expression signatures associated to melanoma lymph node metastatic cells on sEV have never been defined. Therefore, in this work we have characterized the gene expression profile and the proteomic signature associated with sEV in the lymph node metastatic model B16-F1R2 [17]. Analysis of the mRNAs over-expressed in the cells and proteins hyper-secreted in $\mathrm{sEV}$ showed a signature related to ECM and processes linked to tumor-microenvironment interaction. Among all the proteins observed in the signature, we focused our analysis on EMILIN-1 due to its rel- 
evance in processes such as ECM remodeling, cell adhesion, lymphatic vessel functionality, and proliferation $[19,22,25,32,33]$.

Importantly, we found that EMILIN-1 was not detected at protein level intracellularly in B16-F1R2, but seems to be proteolyzed and secreted through sEV, suggesting that sEV contributes to the clearance of the protein in tumor cells. Our data show that EMILIN-1 is proteolyzed and secreted in SEV while is still detected at mRNA level but undetectable in sEV from the highly metastatic model B16-F10. These results suggest that EMILIN-1 proteolysis and secretion in sEV favor lymph node metastasis, while additional mechanisms of EMILIN-1 inactivation (e.g., reduction of protein half-life or translational repression) may arise later in highly metastatic models. Interestingly, some studies have suggested that secretion of specific cargo in sEVs may be a mechanism of eliminating tumor suppressor molecules (e.g., miRNAs, proteins) favoring the survival of cancer cells [34-36]. Therefore, we postulated that EMILIN-1 secretion and degradation in sEVs might be a novel mechanism involved in EMILIN-1 inactivation melanoma progression and metastasis.

EMILIN-1 is considered a tumor-suppressor-like protein in skin, cancer, and breast cancer $[19,37,38]$. Studies with the knock-out animal revealed an important role of EMILIN-1 in the microenvironment to prevent tumor growth and spontaneous metastasis models $[19,38]$. Importantly, analysis in EMILIN-1 KO showed that its ablation in the microenvironment promoted tumor progression in skin, melanoma, and colon cancer models [19]. Other few proteins such as Fibulin-2 [39], EMILIN-2 [40], and Decorin [41], are described also to have tumor suppressive functions. Therefore, degradation/downregulation of these proteins could reduce their tumor-suppressive activities. In the case of EMILIN-1, degradation by neutrophil elastase (NE), MMP-3, -9 , and MT1-MMP is already reported [26,29]. In our study, EMILIN-1 secreted in sEVs is proteolyzed; however, the use of NE and MMP inhibitors in vitro in our models did not change the proteolytic pattern (data not shown), suggesting that additional protease activities involved. Defining the EMILIN-1 "degradome" in specific melanoma scenarios could be crucial to find novel inhibitors that may lead to the reactivation of its suppressive activity in vivo. Interestingly, we analyzed the effect of the extracellular vesicle secretion inhibitor GW4869 on the regulation of EMILIN-1 and found that it is accumulated intracellularly after inhibition demonstrating its active secretion in sEVs.

The fact that EMILIN-1 is lost along melanoma progression, suggests its role as a tumor suppressor-like intrinsically. Hence, we studied the role of EMILIN-1 in melanoma cells by analyzing its influence in cell viability and cell cycle assays. We observed that EMILIN-1 overexpression in the B16-F1 cell line reduced cell viability. These results are in agreement with published data defining that EMILIN-1 expression in the ECM reduces cell proliferation in normal and tumor cells $[18,20,29]$. Our analysis of the cell cycle could not define any effect on it, but rather a decrease in cell viability suggesting a metabolic activity. We also analyzed the impact of EMILIN-1 in cell migration. We observed that cells overexpressing EMILIN-1 had no directed migration, suggesting that its overexpression impairs effective migration in melanoma cells. Previous analysis of EMILIN-1 expression in the skin showed that it locates in the dermis, up to the basement membrane, interacting with components of the ECM but also with the anchoring complex suggesting an important role for cell adhesion, migration, proliferation.

Notably, we observed a significant decrease in tumor growth in B16-F1 cells overexpressing EMILIN-1. Importantly, analysis of experimental lymph node metastasis after footpad injection showed a significant decrease in both models B16-F1R2-R914W and B16F1-HA-E1. These data support that besides a tumor suppressor-like protein, EMILIN-1 has an important effect on reducing lymph node metastasis. Analysis of the main genes affected after EMILIN-1 overexpression may be interesting to define the mechanism involved in metastasis suppression.

Altogether, our data support that EMILIN-1 proteolysis and secretion in sEVs reduce its tumor- and metastatic suppressive-like properties favoring cell viability, effective migration, tumor growth, and lymph node metastasis in mouse melanoma cells. We propose 
a novel and not previously defined intrinsic tumor-suppressive activity of EMILIN-1 in melanoma cells that is abolished by its proteolysis and secretion in sEVs favoring tumor progression and metastatic behavior.

Studies of EMILIN-1 expression in ductal invasive breast cancer carcinoma showed decreased production of Emilin1 mRNA and protein in grade II and III tumors compared to control [42]. Similarly, increased expression of EMILIN-1 among other twelve stromal proteins were associated with low proliferation in non-small cell lung cancer (NSCLC) [43]. These data suggest that decreased production of EMILIN-1 in some tumor types is related to the higher proliferation of tumor cells in breast and lung cancer. So far, the relevance of EMILIN-1 in human melanoma is not reported, our data support a role as suppressor intrinsically as previously reported in the microenvironment [19]. Our work is the first one reporting EMILIN-1 in secreted EVs, due to the relevance of circulating EVs as biomarkers in melanoma patients including nucleic acids and proteins $[24,31,44,45]$, it would be interesting to analyze EMILIN-1 in circulating EVs. Further analysis determining EMILIN-1 stability, degradation, and its secretion in circulating exosomes may help in defining these details. Similarly, analysis of EMILIN-1 expression and its correlation with clinical data (e.g., mutational status, grade, etc.) would be helpful to correlate its expression with the outcome, recurrence, or response to therapy.

\section{Methods}

\subsection{Cell Lines}

B16-F1 and B16-F10 were purchased from American Type Culture Collection (ATCC). The lymph node metastatic variant B16-F1R2 was kindly provided by Dr. Michael Detmar and Dr. Steven Proulx (ETH Zurich, Switzerland) [17]. Spontaneously immortalized mouse melanocytes cell line (melan-a) was kindly provided by Dr. Dorothy C Bennett, (St. George's University of London). All melanoma cell lines were grown in high glucose DMEM (Lonza, Switzerland, \#D6429) supplemented with 10\% fetal bovine serum (Hyclone, Gibco, Waltham, MA, USA \#SH30071.03IH), $2 \mathrm{mM}$ glutamine, and $20 \mu \mathrm{g} / \mathrm{mL}$ gentamicin (Sigma, St Louis, MO, USA \#G1272). The melan-a cell line was cultured in RPMI (Gibco, \#11875-093), supplemented with 5\% fetal calf serum (Gibco \#16030074) and $200 \mathrm{nM} 12$ Otetradecanoyl phorbol-13-acetate (Sigma \#16561-29-8). All cells were grown at $37^{\circ} \mathrm{C}$ in a humidified $5 \% \mathrm{CO}_{2}$ atmosphere and routinely tested for mycoplasma contamination.

\section{2. sEVs Purification}

Cells were cultured in a medium supplemented with $10 \% \mathrm{sEV}$-reduced fetal bovine serum (Hyclone \#SH30071.03IH). FBS was reduced from bovine sEVs by ultracentrifugation at $100,000 \times g$ for $70 \mathrm{~min}$. For sEV isolation, the conditioned medium for $72 \mathrm{~h}$ was centrifuged at $500 \times g$ for $10 \mathrm{~min}$ RT to remove cell contaminants. Then, to remove big debris and microvesicles the supernatant fraction was centrifuged at $12,000 \times g$ for $20 \mathrm{~min}$ at $10{ }^{\circ} \mathrm{C}$. SEVs were then harvested by ultracentrifugation at $100,000 \times g$ for $70 \mathrm{~min}$. The sEVs pellet was washed in $20 \mathrm{~mL}$ of PBS and sEVs were collected by ultracentrifugation at $100,000 \times g$ for $70 \mathrm{~min}$. All ultracentrifuge spins were performed at $10^{\circ} \mathrm{C}$ using a Beckman (Brea, CA, USA) Optima $\times 100$ centrifuge with Beckman TYPE 70.1 Ti rotor. The final sEVs pellet was resuspended in $100 \mu \mathrm{L}$ of PBS and the protein content was measured by bicinchoninic acid assay (Pierce ${ }^{\mathrm{TM}}$ BCA Protein Assay Kit, Thermo Fisher Scientific, Waltham, MA, USA). The NS500 nanoparticle characterization system (NanoSight, Malvern Panalytical, Malvern, UK) equipped with a blue laser (405 nm) was used for real-time characterization of the vesicles.

\subsection{Sample Preparation for Proteomic Analysis}

Proteins were solubilized using $8 \mathrm{M}$ urea in $100 \mathrm{mM}$ Tris- $\mathrm{HCl} \mathrm{pH}$ 8.0. Samples $(10 \mu \mathrm{g})$ were digested by means of the standard FASP protocol (43). Briefly, proteins were reduced and alkylated (15 mM TCEP, $30 \mathrm{mM} \mathrm{CAA,} 30 \mathrm{~min}$ in the dark, RT); and sequentially digested with Lys-C (FUJIFILM Wako Pure Chemical Corporation, Osaka, Japan) (protein:enzyme 
ratio 1:50, $\mathrm{o} / \mathrm{n}$ at RT) and trypsin (Promega, Madison, WI, USA) (protein:enzyme ratio 1:50, $6 \mathrm{~h}$ at $37^{\circ} \mathrm{C}$ ). The resulting peptides were desalted using C18 stage-tips.

\subsection{Mass Spectrometry}

LC-MS/MS was done by coupling a nanoLC-Ultra 1D+ system (Sciex, MA, USA) to a LTQ Orbitrap Velos mass spectrometer (Thermo Fisher Scientific) via a Nanospray Flex source (Thermo Fisher Scientific). Peptides were loaded into a trap column (NS-MP-10 BioSphere C18 $5 \mu \mathrm{m}, 20 \mathrm{~mm}$ length, NanoSeparations, Nieuwkoop, Netherlands) for $10 \mathrm{~min}$ at a flow rate of $2.5 \mu \mathrm{L} / \mathrm{min}$ in $0.1 \% \mathrm{FA}$. Then peptides were transferred to an analytical column (ReproSil Pur C18-AQ $2.4 \mu \mathrm{m}, 500 \mathrm{~mm}$ length and $0.075 \mathrm{~mm}$ ID) and separated using a 120 min linear-gradient (buffer A: 4\% ACN, 0.1\% FA; buffer B: 100\% ACN, $0.1 \%$ FA) at a flow rate of $250 \mathrm{~nL} / \mathrm{min}$. The gradient used was: $0-2 \min 6 \% \mathrm{~B}, 2-103 \min 30 \% \mathrm{~B}$, $103-113 \mathrm{~min} 98 \% \mathrm{~B}, 113-120 \mathrm{~min} 2 \% \mathrm{~B}$. The peptides were electrosprayed (1.8 kV) into the mass spectrometer with a PicoTip emitter (360/20 Tube OD/ID $\mu \mathrm{m}$, tip ID $10 \mu \mathrm{m})$ (Scientific Instrument Services, MA, USA), a heated capillary temperature of $325^{\circ} \mathrm{C}$ and S-Lens RF level of $60 \%$. The mass spectrometer was operated in a data-dependent mode, with an automatic switch between MS and MS/MS scans using a top 15 method (threshold signal $\geq 800$ counts and dynamic exclusion of $45 \mathrm{~s}$ ). MS spectra $(350-1500 \mathrm{~m} / \mathrm{z}$ ) were acquired in the Orbitrap with a resolution of 60,000 FWHM $(400 \mathrm{~m} / \mathrm{z})$. Peptides were isolated using a 1.5 Th window and fragmented using collision-induced dissociation (CID) with linear ion trap read out at a NCE of 35\% (0.25 Q-value and $10 \mathrm{~ms}$ activation time). The ion target values were 1E6 for MS (500 ms max injection time) and 5000 for MS/MS (100 ms max injection time). Samples were analyzed twice.

\subsection{Proteomic Data Analysis}

Raw files were processed with MaxQuant (v1.5.3.30) using the standard settings against a mouse (UniProtKB/Swiss- Prot/TrEMBL, August 2014, 43,539 sequences) protein database, supplemented with contaminants. Label-free quantification was performed with a match between runs (match window of $0.7 \mathrm{~min}$ and alignment window of $20 \mathrm{~min}$ ). Carbamidomethylation of cysteines was set as a fixed modification whereas methionine oxidation and $\mathrm{N}$-term acetylation were variable protein modifications. The minimal peptide length was set to 7 amino acids and a maximum of two tryptic missed-cleavages were allowed. The results were filtered at $0.01 \mathrm{FDR}$ (peptide and protein level). Afterward, the "proteinGroup.txt" file was loaded in Perseus (v1.5.1.6) for further statistical analysis. A minimum of four LFQ valid values per group was required for quantification. Missing values were imputed from the observed normal distribution of intensities. Then, a twosample Student's T-Test with a permutation-based FDR was performed. Only proteins with a $q$-value $<0.1$ and $\log 2$ ratio $>1$ or $<-1$ were considered as regulated. The mass spectrometry proteomics data have been deposited to the ProteomeXchange Consortium via the PRIDE partner repository with the dataset identifier PXD018891.

\subsection{RNA Sequencing (RNA-Seq) and Bioinformatics Analysis}

Total RNA was isolated from cells using the RNeasy Mini Kit (Qiagen, Hilden, Germany \#74106). The quantity and quality of the extracted RNA was assessed using NanoDrop ND-1000 Spectrophotometer (Thermo Fisher Scientific) and Agilent 2100 Bioanalyzer. RNA sequencing (RNA-seq) was performed by the CNIO Genomics Unit. $1 \mu \mathrm{g}$ of total RNA from each sample was used. PolyA+ fraction was purified and randomly fragmented, converted to double-stranded cDNA, and processed through subsequent enzymatic treatments of end-repair, dA tailing, and ligation to adapters as in Illumina's "TruSeq Stranded mRNA Sample Preparation Part \# 15031047 Rev. D" kit (this kit incorporates dUTP during 2nd strand cDNA synthesis, which implies that only the cDNA strand generated during 1st strand synthesis is eventually sequenced). The adapter-ligated library was completed by PCR with Illumina PE primers (8 cycles). The resulting purified cDNA library was applied to an Illumina flow cell for cluster gen- 
eration and sequenced using the Illumina HiSeq2500 platform by following the manufacturer's protocols. 50bp single-end sequenced reads were analyzed with the nextpresso pipeline [46] as follows: sequencing quality was checked with FastQC v0.10.1 (http:/ / www.bioinformatics.babraham.ac.uk/projects/fastqc/, accessed on 10 February 2017). Reads were aligned to the mouse genome (NCBI37/mm9) with TopHat-2.0.10 [47] using Bowtie 1.0.0 [48] and Samtools 0.1.1.9 [49] allowing two mismatches and 20 multihits. Differential expression was calculated with DESeq2 [50]. GSEAPreranked [51] was used to perform gene set enrichment analysis of the described gene signatures on a pre-ranked gene list, setting 1000 gene set permutations. Only those gene sets with significant enrichment levels (FDR $q$-value $<0.1$ ) were finally considered. Access to RNA-seq data is provided from the Gene Expression Omnibus, under the ID GSE150221.

\subsection{Proteomic and RNAseq Integration}

We integrated the profiles associated with lymph node metastatic mouse model (B16F1 vs. B16-F1R2) data from RNAseq and proteomic analysis. Results were represented as the correlation of the ratios at the protein and at the RNAseq level (in log2).

\subsection{Gene Expression Analysis/Quantitative Real-Time PCR Analysis}

Cell lines were analyzed for specific gene expression using pre-designed primers listed below: EMILIN-1 (Fw 5'-CCTGTCTGGCTCCAGTGC-3' ${ }^{\prime}$, Rv 5'-GCTCTAGCTGCTGCACC TTC-3') and Hprt (Fw 5'-TCCTCCTCAGACCGCTTTT-3', Rv 5'-CCTGGTTCATCATCGCT AATC- $\left.3^{\prime}\right)$. In brief, total RNA was extracted from tissues or cells as described above and reverse-transcribed using the QuantiTect Reverse Transcription Kit (Qiagen \#205313). Quantitative real-time PCR (QRT-PCR) was performed on a 7500 Fast Real Time PCR System (Applied Biosystems, Waltham, MA, USA), using SYBER Green Universal PCR Master Mix (Life Technologies, Carlsbad, CA, USA \#4304437). Gene expression was analyzed using the delta-deltaCT method for relative quantification and all samples were normalized to a housekeeping gene, Hprt.

\subsection{Western Blot Analysis and Antibodies}

Cells were lysed with RIPA buffer containing a complete protease and phosphatase inhibitor tablet (Roche, Basel, Switzerland, \#11836153001, \#PHOSS-RO). Lysates were cleared by centrifugation at $14,000 \times q$ for $15 \mathrm{~min}$ at $5{ }^{\circ} \mathrm{C}$. Supernatant fractions were used for Western blot. Protein extracts or purified sEVs were quantified for protein content using the bicinchoninic acid assay (Pierce ${ }^{\mathrm{TM}}$ BCA Protein Assay Kit, Thermo Fisher Scientific \#23225). Equal amounts of cell lysate or purified sEVs were resolved by SDS-PAGE and transferred into a polyvinylidene difluoride (PVDF) membrane (Millipore \#IPVH00010). After blocking with 5\% milk for $1 \mathrm{~h}$ RT, membranes were incubated with the antibody As556 IgG EMILIN-1 (Rabbit Polyclonal from CRO, Italy, 1/2000) overnight at $4{ }^{\circ} \mathrm{C}$. Antibodies to $\beta$-actin (Mouse Monoclonal, \#A5441 (Sigma), 1/10,000) for cells, and Alix 3A9 (Mouse Monoclonal, \#2171S (Cell Signaling), 1/1000) for sEVs, were used as loading controls. The intensities of the immunoreactive bands were quantified by densitometry using ImageJ software v1.8.0 (NIH, LOCI, University of Wisconsin, Public Domain, BSD-2, https:/ / imagej.nih.gov/ij/download.html, accessed on 30 May 2021).

\subsection{Immunofluorescence}

Cells were fixed with $4 \%$ paraformaldehyde (PFA, Electron Microscopy Sciences) for $20 \mathrm{~min}$ at RT, followed by permeabilization with $0.1 \%$ Triton X-100 (Sigma \#11332481001) in PBS for 10 min RT. After washing with PBS, to avoid antibody unspecific interactions coverslips were incubated with PBS 5\% Donkey Serum (Sigma \#D9663), 1\% BSA, and $0.05 \%$ Triton for $45 \mathrm{~min}$ at RT and stained with primary antibody As556 IgG EMILIN-1 (Rabbit Polyclonal from CRO, Italy, $1 / 2000) 4{ }^{\circ} \mathrm{C}$ overnight. Then, samples were rinsed and incubated with an Alexa Fluor 488 conjugated secondary antibody (Donkey, Rabbit IgG \#A21206 (Life Technologies), 1/200). 40,6-diamidino-2-phenylindole (DAPI) was used for 
nuclear staining. Digitalized images were generated using a Leica TCS SP5 X AOBS or Leica TCS SP5 AOBS confocal microscopes (63X HCXPLAPO 1.4 N.A) and analyzed using Fiji software (Open source, https: / /imagej.net/software / fiji/, accessed on 30 May 2021) [52].

\subsection{GW4869 Treatment In Vitro}

Melanoma cells were treated for $24 \mathrm{~h}$ with the inhibitor GW4869 (Selleckchem, Houston, TX, USA \#S7609) at $10 \mu \mathrm{M}$ per $3 \times 10^{5}$ of cells seeded in 6-well plates. PBS-DMSO was added as a control. After the treatment, cells were stained following the protocol of immunofluorescence previously described. Digitalized images were generated using a Leica TCS SP8 FSU AOBS confocal microscope and analyzed using Fiji software [52].

\subsection{MG-132 Treatment In Vitro}

Melanoma cells were treated for 16h with the inhibitor MG-132 (Sigma \#1211877-369) at $8 \mu \mathrm{M}$ per $3 \times 10^{5}$ of cells seeded in 6-well plates. PBS-DMSO was added as a control. After the treatment, cells were stained following the protocol of immunofluorescence previously described. Digitalized images were generated using a Leica TCS SP8 FSU AOBS confocal microscope and analyzed using Fiji software [52].

\subsection{Plasmids Design and Cloning Strategies}

For the generation of HA-EMILIN-1 transfectants, B16-F1 GFP-luc cell line was transfected with pCMV3- N-HA (N-terminal HA-tagged) plasmid (Sinobiological, Wayne, PA, USA \#CV017) in which human EMILIN-1 full sequence cDNA was cloned, the control cell line was generated using the empty vector pCMV3-N-HA. The cloning and primers designed for the generation of the vector and the insert fragments sharing overlapping were done following Gibson Assembly NEB protocol (New England Biolabs, Ipswich, MA, USA \#E2611S/L) and SnapGene®Software (GSL Biotech LLC, San Diego, CA, USA). For transfection experiments, we used the Lipofectamine 2000 Transfection Reagent (Thermo Fisher \#11668019). The transfection was done in suspension, where $5 \times 10^{5}$ B16-F1R2 GFP-luc cells were seeded in a T6 multi-well with $8 \mu \mathrm{L}$ of Lipofectamine reagent and $8 \mu \mathrm{g}$ of DNA (ratio 1:1 according to manufacturer's protocol). $16 \mathrm{~h}$ later, the medium was removed, and fresh medium was added. Neomycin (G-418 Sigma \#G8168) selection were added 48h later at $2 \mathrm{mg} / \mathrm{mL}$ and $500 \mu \mathrm{g} / \mathrm{mL}$, during 14 days. Stable transfected clones were isolated from the selected cells using "cloning cylinders" (Sigma \#CLS31668) and tripsinization. The primers used for cloning were: EMILIN-1 Fw 5'-TGGAGCTCTGGCTTATCCTTACGACGTGCCTGACTACGCCatggcccccegcaccctctg3', EMILIN-1 Rv 5'-GAGGGGCAAACAACAGATGGCTGGCAACTAGAAGGCACAGctac gcgtgttcaagctctggg-3', bGH (poly A) Fw 5'-CTGTGCCTTCTAGTTGCCAGCC-3', HAtag Rv 5'-GGCGTAGTCAGGCACGTCGTA-3'. Two different polymerases were used due to the length of the vector. Platinium SuperFi DNA polymerase (Invitrogen, Waltham, MA, USA, \#12351010) was used for vector amplification following the 3-steps protocol $(<10 \mathrm{~kb})$ and Platinum ${ }^{\mathrm{TM}}$ Pfx DNA Polymerase (Life Technologies \#11708021) was used for the insert. The number of fragments used for assembly was $100 \mathrm{ng}$ of the vector and $150 \mathrm{ng}$ of EMILIN1 insert. For the generation of R914W mutant, we performed a site-directed mutagenesis following QuickChange II Sited-Directed Mutagenesis protocol (Agilent Technologies, Santa Clara, CA, USA, \#200523). The primers used for site-directed mutagenesis were: R914W Fw 5'-AAGTGGAGGCCGTGCTGTCCTGGTCCAACCAGGGCGTGGCCCGC-3', R914W Rv 5'-GCGGGCCACGCCCTGGTTGGACCAGGACAGCACGGCCTCCACTT-3'. Cells were transformed and positive clones were confirmed by DNA sequencing.

\subsection{Cell Viability Assay}

Luminescent Cell Viability Assay, CellTiter-Glo, (Promega \#G7570) at different time points $(24,48,72 \mathrm{~h})$ following manufacturer protocol. The CellTiter-Glo ${ }^{\circledR}$ Luminescent Cell Viability Assay is a method to determine the number of viable cells in culture based on quantitation of the ATP present, which signals the presence of metabolically active cells. 
Cells were seeded into a T96-well plate and luminescence was measured at X $490 \mathrm{~nm}$ in a VICTOR Multilabel Plate Reader (Perkin Elmer, Waltham, MA, USA).

\subsection{Cell Cycle}

Cell cycle histograms for bulk DNA staining (PI), after addition of EdU, from B16-F1HA and B16-F1-HA-E1 model were performed at 24, 48, 72, $96 \mathrm{~h}$, and one week following manufacture protocol (Invitrogen \#C10337). The percentage of B16-F1-HA and B6-F1-HAE1 cells in the $S$ phase was calculated. The modified thymidine analog EdU was added $30 \mathrm{~min}$ before cell fixation. Cells were fixed by adding $100 \mu \mathrm{L}$ PFA 4\% (in PBS, freshly prepared) and Streptavidin-AF647 (Vector) was used after the EdU detection mix step. Data were acquired on BD FACS Canto II, at least 5000 single alive events were acquired and all data was analyzed using FlowJo ${ }^{\circledR}$ software v10 (BD, Ashland, OR, USA).

\subsection{Cell Tracking and Motility Assay}

Cell tracking and motility analysis were performed overnight in chamber slide with a IBIDI $\mu$-Slide 8 Well (\#80826). Videos were acquired in DM6000B Widefield microscope 20X HCXPLAPO 0.7 N.A. (Leica Microsystems). For each cell model it has been required a cell identification and trajectory reconstruction. It has been performed well on live-cell, time-lapse, phase contrast video microscopy of hundreds of cells in parallel. Three or four positions were selected from the videos acquired. Cell position, distance and velocity were measured and analyzed from each position selected by using ImageJ software v1.8.0.

\subsection{Xenograft Studies}

All animal experiments were performed according to protocols approved by the Institutional Ethics Committee for Research and Animal Welfare (CEIyBA) of the CNIO, the Instituto de Salud Carlos III (CNIO-ISCIII), and the Comunidad Autónoma de Madrid (CAM).

\subsection{Tumor Growth and Metastasis Studies}

8 to 10 week-old C57BL/6J.OlaHsd male mice were injected in the flank with $1 \times 10^{6}$ melanoma cells. Tumor volume was monitored 2-3 times per week. To analyze the metastatic spread through the lymphatic system, 8 to 10 week-old C57BL/6J.OlaHsd male mice were injected intra-footpad with $2 \times 10^{4}$ melanoma cells. Animals were sacrificed 21 days after injection. Luciferase imaging was done ex vivo using the IVIS Spectrum system in both approaches. Popliteal lymph nodes were paraffin-embedded and stained with HMB45, the percentage of melanoma positive cells quantification was also performed.

\subsection{In Vivo Imaging System}

Luciferase imaging was performed using the IVIS Spectrum system (Caliper, Xenogen). Tumor-bearing mice were anesthetized (using isoflurane $3-4 \%$ and $0.5 \% \mathrm{O}_{2}$ ), and $\mathrm{D}$ luciferin (50 mg kg $\mathrm{mg}^{-1}$ in $100 \mu \mathrm{L}$ PBS) was administered. Eight minutes later, mice were euthanized and their organs were analyzed for luciferase expression. Data were quantified with Living Imaging ${ }^{\circledR}$ software 4.7.2 (Perkin Elmer).

\subsection{Histological Studies}

Tissue samples were fixed in 10\% neutral buffered formalin (4\% formaldehyde in solution), paraffin-embedded and cut at $3 \mu \mathrm{m}$, mounted in superfrost ${ }^{\circledR}$ plus slides, and dried overnight. For different staining methods, slides were deparaffinized in xylene and re-hydrated through a series of graded ethanol until water. Consecutive sections were stained with hematoxylin and eosin (H\&E), and several immunohistochemistry reactions were performed in an automated immunostaining platform (Autostainer Link 48, Dako; Ventana Discovery XT, Roche). Antigen retrieval was first performed with the appropriate pH buffer, (Low pH buffer, Dako; CC1m, Ventana, Roche) and endogenous peroxidase was blocked (peroxide hydrogen at 3\%). Then, slides were incubated with the appropriate primary antibody As556 IgG EMILIN-1 (Rabbit Polyclonal from CRO, Italy). After the 
primary antibody, slides were incubated with the corresponding secondary antibodies. The immunohistochemical reaction was developed using 3, 30-diaminobenzidine tetrahydrochloride (DAB) or Purple Kit (Chromo Map DAB or Purple Kit, Ventana, Roche; DAB (Dako), and nuclei were counterstained with Carazzi's hematoxylin. Finally, the slides were dehydrated, cleared, and mounted with a permanent mounting medium for microscopic evaluation. Positive control sections known to be primary antibody positive were included for each staining run. The intensity of EMILIN-1 expression in tumors was analyzed and scanned using ZEISS ZEN Microscope software, intensity above average was considered as high expression and below average as low.

\subsection{Statistical Analyzes}

Error bars in the graphical data represent means \pm s.e.m. Mouse experiments were performed using at least three mice per treatment group. $p$ values of $p<0.05$ were considered statistically significant by Student's $t$ test or ANOVA. For the tumor growth analyzes, we performed two-way ANOVA statistical analyzes using GraphPad Prism®software v8.3.0. (GraphPad Software, San Diego, CA, USA)

Supplementary Materials: The following are available online at https:/ /www.mdpi.com/article/10 .3390/ijms22147406/s1.

Author Contributions: A.A.L., M.S.M., A.C., M.H.-R. performed experiment and data analysis P.X.E., J.M., F.A.-S. performed proteomic data analysis, D.M. helped with microscopy analysis, J.Á.R., E.M., R.D., P.S. contributed to the scientific discussion of the work and H.P. conceived and directed the study. A.A.L. and H.P. planed the experiments and wrote the manuscript. All authors contributed to and approved the final version of the manuscript. All authors have read and agreed to the published version of the manuscript.

Funding: The authors gratefully acknowledge the support of the following sources of funding: Fundación Ramon Areces, MINECO (SAF2014-54541-R), Ramón y Cajal Programme, Asociación Española Contra el Cáncer, Constantes y Vitales (ATRES MEDIA/AXA Foundation) and FERO Foundation. We are also grateful for the support of the support of the Translational NeTwork for the CLinical application of Extracellular VesicleS, TeNTaCLES. RED2018-102411-T (AEI/10.13039/501100011033) and MINECO-Severo Ochoa predoctoral program to support A.A.L thesis and short term stay in Italy to perform this study. The CNIO, certified as Severo Ochoa Excellence Centre, is supported by the Spanish Government through the Instituto de Salud Carlos III (ISCIII).

Institutional Review Board Statement: All animal experiments were performed according to protocols approved by the Institutional Ethics Committee for Research and Animal Welfare (CEIyBA) of the CNIO (IACUC.010-2015), the Instituto de Salud Carlos III (CBA19_2015-v2), and the Comunidad Autónoma de Madrid (PROEX 178/15).

Informed Consent Statement: Not applicable.

Data Availability Statement: All reagents/models used in this work are available, please contact Peinado.

Acknowledgments: We thank the members of Hector Peinado's laboratory for helpful discussions. We thank Marisol Soengas (CNIO) and the members of her laboratory for their helpful discussions. We thank Michael Detmar (ETH, Zurich) for providing mouse B16F1-R2 cell line and Dorothy C Bennett, (St. George's University of London) for providing the melan-a cell line. We thank Marcos Malumbres (CNIO) and his laboratory for their support in cell cycle analysis. We thank Miguel Quintanilla (IIB, Madrid), Miguel Angel del Pozo (CNIC, Madrid) and Marisol Soengas (CNIO, Madrid) for being part of A.A.L thesis committee.

Conflicts of Interest: The authors declare no competing financial interests.

\section{References}

1. Joyce, J.A.; Pollard, J.W. Microenvironmental regulation of metastasis. Nat. Rev. Cancer 2009, 9, 239-252. [CrossRef]

2. Peinado, H.; Zhang, H.; Matei, I.R.; Costa-Silva, B.; Hoshino, A.; Rodrigues, G.; Psaila, B.; Kaplan, R.N.; Bromberg, J.F.; Kang, Y.; et al. Pre-metastatic niches: Organ-specific homes for metastases. Nat. Rev. Cancer 2017, 17, 302-317. [CrossRef] [PubMed] 
3. Peinado, H.; Lavotshkin, S.; Lyden, D. The secreted factors responsible for pre-metastatic niche formation: Old sayings and new thoughts. Semin. Cancer Biol. 2011, 21, 139-146. [CrossRef] [PubMed]

4. $\quad$ Becker, A.; Thakur, B.K.; Weiss, J.M.; Kim, H.S.; Peinado, H.; Lyden, D. Extracellular Vesicles in Cancer: Cell-to-Cell Mediators of Metastasis. Cancer Cell 2016, 30, 836-848. [CrossRef]

5. Colombo, M.; Raposo, G.; Thery, C. Biogenesis, secretion, and intercellular interactions of exosomes and other extracellular vesicles. Annu. Rev. Cell Dev. Biol. 2014, 30, 255-289. [CrossRef]

6. Thery, C.; Zitvogel, L.; Amigorena, S. Exosomes: Composition, biogenesis and function. Nat. Rev. Immunol. 2002, 2, 569-579. [CrossRef] [PubMed]

7. Witwer, K.W.; Théry, C. Extracellular vesicles or exosomes? On primacy, precision, and popularity influencing a choice of nomenclature. J. Extracell. Vesicles 2019, 8, 1648167. [CrossRef] [PubMed]

8. Raposo, G.; Stoorvogel, W. Extracellular vesicles: Exosomes, microvesicles, and friends. J. Cell Biol. 2013, 200, 373-383. [CrossRef] [PubMed]

9. Camussi, G.; Deregibus, M.C.; Bruno, S.; Cantaluppi, V.; Biancone, L. Exosomes/microvesicles as a mechanism of cell-to-cell communication. Kidney Int. 2010, 78, 838-848. [CrossRef]

10. Thery, C.; Witwer, K.W.; Aikawa, E.; Jose Alcaraz, M.; Anderson, J.D. Minimal information for studies of extracellular vesicles 2018 (MISEV2018): A position statement of the International Society for Extracellular Vesicles and update of the MISEV2014 guidelines. J. Extracell. Vesicles 2018, 7, 1535750. [CrossRef]

11. Sleeman, J.P. The lymph node pre-metastatic niche. J. Mol. Med. 2015, 93, 1173-1184. [CrossRef] [PubMed]

12. Van Akkooi, A.C.; Verhoef, C.; Eggermont, A.M. Importance of tumor load in the sentinel node in melanoma: Clinical dilemmas. Nat. Rev. Clin. Oncol. 2010, 7, 446-454. [CrossRef] [PubMed]

13. Eccles, S.; Paon, L.; Sleeman, J. Lymphatic metastasis in breast cancer: Importance and new insights into cellular and molecular mechanisms. Clin. Exp. Metastasis 2007, 24, 619-636. [CrossRef]

14. Sleeman, J.P.; Cremers, N. New concepts in breast cancer metastasis: Tumor initiating cells and the microenvironment. Clin. Exp. Metastasis 2007, 24, 707-715. [CrossRef]

15. Hood, J.L.; San, R.S.; Wickline, S.A. Exosomes released by melanoma cells prepare sentinel lymph nodes for tumor metastasis. Cancer Res. 2011, 71, 3792-3801. [CrossRef]

16. Pucci, F.; Garris, C.; Lai, C.P.; Newton, A.; Pfirschke, C.; Engblom, C.; Alvarez, D.; Sprachman, M.; Evavold, C.; Magnuson, A.; et al. SCS macrophages suppress melanoma by restricting tumor-derived vesicle-B cell interactions. Science 2016, 352, $242-246$. [CrossRef]

17. Liersch, R.; Shin, J.W.; Bayer, M.; Schwoppe, C.; Schliemann, C.; Berdel, W.E.; Mesters, R.; Detmar, M. Analysis of a novel highly metastatic melanoma cell line identifies osteopontin as a new lymphangiogenic factor. Int. J. Oncol. 2012, 41, $1455-1463$. [CrossRef]

18. Capuano, A.; Pivetta, E.; Sortori, G.; Bosisio, G.; Favero, A.; Cover, E.; Andreuzzi, E.; Colombatti, A.; Cannizzaro, R.; Scanziani, E.; et al. Abrogation of EMILIN1-beta1 integrin interaction promotes experimental colitis and colon carcinogenesis. Matrix Biol. 2019, 83, 97-115. [CrossRef] [PubMed]

19. Danussi, C.; Petrucco, A.; Wassermann, B.; Modica, T.M.; Pivetta, E.; Del Bel Belluz, L.; Colombatti, A.; Spessotto, P. An EMILIN1negative microenvironment promotes tumor cell proliferation and lymph node invasion. Cancer Prev. Res. 2012, 5, 1131-1343. [CrossRef] [PubMed]

20. Danussi, C.; Petrucco, A.; Wassermann, B.; Pivetta, E.; Modica, T.M.; Del Bel Belluz, L.; Colombatti, A.; Spessotto, P. EMILIN1alpha4/alpha9 integrin interaction inhibits dermal fibroblast and keratinocyte proliferation. J. Cell Biol. 2011, 195, 131-145. [CrossRef]

21. Spessotto, P.; Bulla, R.; Danussi, C.; Radillo, O.; Cervi, M.; Monami, G.; Bossi, F.; Tedesco, F.; Doliana, R.; Colombatti, A. EMILIN1 represents a major stromal element determining human trophoblast invasion of the uterine wall. J. Cell Sci. 2006, 119 Pt 21, 4574-4584. [CrossRef]

22. Pivetta, E.; Wassermann, B.; Del Bel Belluz, L.; Danussi, C.; Modica, T.M.; Maiorani, O.; Bosisio, G.; Boccardo, F.; Canzonieri, V.; Colombatti, A.; et al. Local inhibition of elastase reduces EMILIN1 cleavage reactivating lymphatic vessel function in a mouse lymphoedema model. Clin. Sci. 2016, 130, 1221-1236. [CrossRef] [PubMed]

23. Fitoussi, R.; Beauchef, G.; Guere, C.; Andre, N.; Vie, K. Localization, fate and interactions of Emilin-1 in human skin. Int. J. Cosmet. Sci. 2019, 41, 183-193. [CrossRef] [PubMed]

24. Peinado, H.; Alečković, M.; Lavotshkin, S.; Matei, I.; Costa-Silva, B.; Moreno-Bueno, G.; Hergueta-Redondo, M.; Williams, C.; García-Santos, G.; Ghajar, C.; et al. Melanoma exosomes educate bone marrow progenitor cells toward a pro-metastatic phenotype through MET. Nat. Med. 2012, 18, 883-891. [CrossRef] [PubMed]

25. Colombatti, A.; Spessotto, P.; Doliana, R.; Mongiat, M.; Bressan, G.M.; Esposito, G. The EMILIN/Multimerin family. Front. Immunol. 2011, 2, 93. [CrossRef] [PubMed]

26. Maiorani, O.; Pivetta, E.; Capuano, A.; Modica, T.M.; Wassermann, B.; Bucciotti, F.; Colombatti, A.; Doliana, R.; Spessotto, P. Neutrophil elastase cleavage of the gC1q domain impairs the EMILIN1-alpha4beta1 integrin interaction, cell adhesion and anti-proliferative activity. Sci. Rep. 2017, 7, 39974. [CrossRef] [PubMed]

27. Hofmann, U.B.; Westphal, J.R.; Van Muijen, G.N.; Ruiter, D.J. Matrix metalloproteinases in human melanoma. J. Investig. Derm. 2000, 115, 337-344. [CrossRef] 
28. Moro, N.; Mauch, C.; Zigrino, P. Metalloproteinases in melanoma. Eur. J. Cell. Biol. 2014, 93, 23-29. [CrossRef]

29. Pivetta, E.; Danussi, C.; Wassermann, B.; Modica, T.M.; Del Bel Belluz, L.; Canzonieri, V.; Colombatti, A.; Spessotto, P. Neutrophil elastase-dependent cleavage compromises the tumor suppressor role of EMILIN1. Matrix Biol. 2014, 34, 22-32. [CrossRef]

30. Tkach, M.; Théry, C. Communication by Extracellular Vesicles: Where We Are and Where We Need to Go. Cell 2016, 164, 1226-1232. [CrossRef] [PubMed]

31. Garcia-Silva, S.; Benito-Martín, A.; Sánchez-Redondo, S.; Hernández-Barranco, A.; Ximénez-Embún, P.; Nogués, L.; Mazariegos, M.S.; Brinkmann, K.; Amor López, A.; Meyer, L.; et al. Use of extracellular vesicles from lymphatic drainage as surrogate markers of melanoma progression and BRAF (V600E) mutation. J. Exp. Med. 2019, 216, 1061-1070. [CrossRef]

32. Capuano, A.; Pivetta, E.; Baldissera, F.; Bosisio, G.; Wassermann, B.; Bucciotti, F.; Colombatti, A.; Sabatelli, P.; Doliana, R.; Spessotto, P.; et al. Integrin binding site within the gC1q domain orchestrates EMILIN-1-induced lymphangiogenesis. Matrix Biol. 2019, 81, 34-49. [CrossRef]

33. Danussi, C.; Spessotto, P.; Petrucco, A.; Wassermann, B.; Sabatelli, P.; Montesi, M.; Doliana, R.; Bressan, G.M.; Colombatti, A. Emilin1 deficiency causes structural and functional defects of lymphatic vasculature. Mol. Cell. Biol. 2008, 28, 4026-4039. [CrossRef] [PubMed]

34. Kanlikilicer, P.; Rashed, M.H.; Bayraktar, R.; Mitra, R.; Ivan, C.; Aslan, B.; Zhang, X.; Filant, J.; Silva, A.M.; Rodriguez-Aguayo, C.; et al. Ubiquitous Release of Exosomal Tumor Suppressor miR-6126 from Ovarian Cancer Cells. Cancer Res. 2016, 76, 7194-7207. [CrossRef]

35. Dean, I.; Dzinic, S.H.; Bernardo, M.M.; Zou, Y.; Kimler, V.; Li, X.; Kaplun, A.; Grannerman, J.; Mao, G.; Sheng, S. The secretion and biological function of tumor suppressor maspin as an exosome cargo protein. Oncotarget 2017, 8, 8043-8056. [CrossRef] [PubMed]

36. Gabriel, K.; Ingram, A.; Austin, R.; Kapoor, A.; Tang, D.; Majeed, F.; Qureshi, T.; Al-Nedawi, K. Regulation of the tumor suppressor PTEN through exosomes: A diagnostic potential for prostate cancer. PLoS ONE 2013, 8, e70047.

37. Sun, B.; Zhou, Y.; Fang, Y.; Li, Z.; Gu, X.; Xiang, J. Colorectal cancer exosomes induce lymphatic network remodeling in lymph nodes. Int. J. Cancer 2019, 145, 1648-1659. [CrossRef] [PubMed]

38. Rabajdova, M.; Urban, P.; Spakova, I.; Saksun, L.; Dudic, R.; Ostro, A.; Caprnda, M.; Kruzliak, P.; Adamek, M.; Marekova, M. The crucial role of emilin 1 gene expression during progression of tumor growth. J. Cancer Res. Clin. Oncol. 2016, 142, 2397-2402. [CrossRef] [PubMed]

39. Law, E.W.; Cheung, A.K.L.; Kashuba, V.I.; Pavlova, T.V.; Zabarovsky, E.R.; Lung, H.L.; Cheng, Y.; Chua, D.; Kwong, L.D.-W.; Tsao, S.W.; et al. Anti-angiogenic and tumor-suppressive roles of candidate tumor-suppressor gene, Fibulin-2, in nasopharyngeal carcinoma. Oncogene 2012, 31, 728-738. [CrossRef]

40. Marastoni, S.; Andreuzzi, E.; Paulitti, A.; Colladel, R.; Pellicani, R.; Todaro, F.; Schiavinato, A.; Bonaldo, P.; Colombatti, A.; Mongiat, M.; et al. EMILIN2 down-modulates the Wnt signalling pathway and suppresses breast cancer cell growth and migration. J. Pathol. 2014, 232, 391-404. [CrossRef]

41. Neill, T.; Schaefer, L.; Iozzo, R.V. Oncosuppressive functions of decorin. Mol. Cell. Oncol. 2015, 2, e975645. [CrossRef]

42. Stegemann, C.; Didangelos, A.; Barallobre-Barreiro, J.; Langley, S.R.; Mandal, K.; Jahangiri, M.; Mayr, M. Proteomic identification of matrix metalloproteinase substrates in the human vasculature. Circ. Cardiovasc. Genet. 2013, 6, 106-117. [CrossRef]

43. Edlund, K.; Lindskog, C.; Saito, A.; Berglund, A.; Pontén, F.; Göransson-Kultima, H.; Isaksson, A.; Jirström, K.; Planck, M.; Johansson, L.; et al. CD99 is a novel prognostic stromal marker in non-small cell lung cancer. Int. J. Cancer 2012, 131, $2264-2273$. [CrossRef]

44. Zocco, D.; Bernardi, S.; Novelli, M.; Astrua, C.; Fava, P.; Zarovni, N.; Carpi, F.M.; Bianciardi, L.; Malavenda, O.; Quaglino, M.; et al. Isolation of extracellular vesicles improves the detection of mutant DNA from plasma of metastatic melanoma patients. Sci. Rep. 2020, 10, 15745. [CrossRef] [PubMed]

45. Bollard, S.M.; Casalou, C.; Goh, C.Y.; Tobin, D.J.; Kelly, P.; McCann, A.; Potter, S.M. Circulating Melanoma-Derived Extracellular Vesicles: Impact on Melanoma Diagnosis, Progression Monitoring, and Treatment Response. Pharmaceuticals 2020, 13 , 475. [CrossRef]

46. Graña, O.; Rubio-Camarillo, M.; Fdez-Riverola, F.; Pisano, D.G.; Glez-Peña, D. Nextpresso: Next Generation Sequencing Expression Analysis Pipeline. Curr. Bioinform. 2018, 13. [CrossRef]

47. Trapnell, C.; Roberts, A.; Goff, L.; Pertea, G.; Kim, D.; Kelley, D.R.; Pimentel, H.; Salzberg, S.; Rinn, J.L.; Pachter, L. Differential gene and transcript expression analysis of RNA-seq experiments with TopHat and Cufflinks. Nat. Protoc. 2012, 7, 562-578. [CrossRef]

48. Langmead, B.; Trapnell, C.; Pop, M.; Salzberg, S.L. Ultrafast and memory-efficient alignment of short DNA sequences to the human genome. Genome Biol. 2009, 10, R25. [CrossRef] [PubMed]

49. Li, H.; Handsaker, B.; Wysoker, A.; Fennell, T.; Ruan, J.; Homer, N.; Marth, G.; Abecasis, G.; Durbin, R. The Sequence Alignment/Map format and SAMtools. Bioinformatics 2009, 25, 2078-2079. [CrossRef] [PubMed]

50. Love, M.I.; Huber, W.; Anders, S. Moderated estimation of fold change and dispersion for RNA-seq data with DESeq2. Genome Biol. 2014, 15, 550. [CrossRef]

51. Subramanian, A.; Tamayo, P.; Mootha, V.K.; Mukherjee, S.; Ebert, B.L.; Gillette, M.A.; Paulovich, A.; Pomeroy, S.L.; Golub, T.R.; Lander, E.S.; et al. Gene set enrichment analysis: A knowledge-based approach for interpreting genome-wide expression profiles. Proc. Natl. Acad. Sci. USA 2005, 102, 15545-15550. [CrossRef]

52. Schindelin, J.; Arganda-Carreras, I.; Frise, E.; Kaynig, V.; Longair, M.; Pietzsch, T.; Preibisch, S.; Rueden, C.; Saalfeld, S.; Schmid, B.; et al. Fiji: An open-source platform for biological-image analysis. Nat. Methods 2012, 9, 676-682. [CrossRef] 